

\title{
Cerebrovascular Accident Complicating Diabetic Ketoacidosis in a Nigerian Adolescent: A Case Report and Review of the Literature
}

\author{
Akinola IJ*1, Akinyosoye $\mathrm{G}^{2}$, Adedokun SA ${ }^{2}$ \\ ${ }^{1}$ Department of Paediatrics and Child Health, Lagos State University College of Medicine, Ikeja, Lagos \\ ${ }^{2}$ Department of Paediatrics, Lagos State University Teaching Hospital, Ikeja, Lagos
}

${ }^{*}$ Correspondence: Dr IJ Akinola, Department of Paediatrics and Child Health, Lagos State University College of

Medicine, Ikeja, Lagos. E-mail: ibironke.akinola@lasucom.edu.ng; ORCID - https://orcid.org/0000-0002-0081-1124.

Summary

Cerebrovascular accident (CVA) is a rare neurological complication of diabetic ketoacidosis (DKA) in the paediatric population. The risk of developing CVA in DKA patients is often increased due to abnormalities in coagulation factors, platelet activation, blood volume and flow, and vascular reactivity. Cerebral oedema, the most common neurological complication of DKA, may also predispose to CVA. We report the case of a -12-year-old adolescent with DKA complicated by CVA. She developed features of right hemispheric CVA while on admission and had radiological confirmation of an ischaemic CVA. This report highlights that cerebrovascular accidents in DKA can easily be missed or confused with cerebral oedema.

Keywords: Cerebral Oedema, Cerebrovascular disease, Hemiplegia, Hyperglycaemia, Stroke, Type 1 Diabetes mellitus.

\section{Introduction}

Diabetic ketoacidosis (DKA) is a well-reported complication of diabetes mellitus in resourcepoor and advanced countries. ${ }^{[1-3]}$ It is a medical emergency that combines the primary underlying mechanism of insulin deficiency with hyperglycaemia, metabolic acidosis, accumulated ketones in the blood or urine and increased anion gap. ${ }^{[4]}$ In a study carried out by Ahuja et al., infections and non-compliance with insulin therapy were the most common risk factors for DKA in children. ${ }^{[5]}$ Other risk factors associated with DKA include socioeconomic disadvantage, female gender, adolescence, high glycosylated haemoglobin (HbA1c), eating disorders and depression. [6] Cerebrovascular accident (CVA) is a rare complication of paediatric DKA. It accounts for about one-tenth of intra-cerebral complications in DKA. [7]

The systemic inflammation in DKA causes vascular endothelial damage, coagulopathy and elevation of inflammatory markers such as CReactive Protein, cytokines (IL6, IL1 $\beta, \mathrm{TNF} a$ ), and complement activation. $[4,8,9]$ Furthermore, the oxidative stress induced by hyperglycaemia and ketosis may lead to tissue ischaemia. ${ }^{[9]}$ Therefore, patients with DKA are predisposed to a higher risk of developing blood hyperviscosity and vascular injury, potential causes of ischaemic 
CVA and haemorrhagic CVA, respectively. Diabetic ketoacidosis complicated by CVA is not necessarily accompanied by cerebral oedema [9], although it may mimic it on presentation as both conditions have overlapping clinical features. Therefore, it is crucial to distinguish CVA in DKA from cerebral oedema as the approach to management differs.

We report the case of a -12-year- old female adolescent with DKA complicated by CVA.

\section{Case Description}

$\mathrm{AP}$, a known patient with Type 1 Diabetes mellitus (T1DM), diagnosed a year prior, presented at the Children Emergency Unit of the Lagos State University Teaching Hospital (LASUTH) in March 2019 with complaints of fever and vomiting of two days duration, generalized body weakness of a day duration, an episode of convulsion and unresponsiveness about 5 hours before presentation. Before referral, she had received an unknown quantity of intravenous fluids in a private hospital.

At presentation, she was unconscious with a Glasgow Coma Score (GCS) of 3/15, and her pupils were sluggishly reactive to light. Lateralizing signs were not observed at presentation. Based on CDC growth charts, the body length and weight were $151 \mathrm{~cm}\left(47^{\text {th }}\right.$ percentile, SD -0.07) and $49 \mathrm{~kg}$ ( $76^{\text {th }}$ percentile. S.D.0.73), respectively. [10] She was febrile (38.30 C), had deep breathing with tachypnoea (respiratory rate of 60 cycles per minute), tachycardia (heart rate of 160 beats per minute but a normal blood pressure of $110 / 70 \mathrm{mmHg}$. The random blood glucose at admission was $338 \mathrm{mg} / \mathrm{dl}$. The full blood count showed neutrophilia (Table I). A diagnosis of DKA with cerebral oedema secondary to sepsis in a known patient with T1DM was made.

Table I: Summary of the results of laboratory investigations at the point of admission

\begin{tabular}{llll}
\hline Parameters & Result & Comment & Reference \\
\hline $\mathrm{Na}$ & $140 \mathrm{mmol} / 1$ & Normal & $133.0-150.0 \mathrm{mmol} / 1$ \\
$\mathrm{~K}$ & $4.2 \mathrm{mmol} / 1$ & Normal & $3.5-5.0 \mathrm{mmol} / 1$ \\
$\mathrm{Cl}$ & $106 \mathrm{mmol} / 1$ & Normal & $96.0-110.0 \mathrm{mmol} / 1$ \\
$\mathrm{Hco} 3$ & $5 \mathrm{mmol} / 1$ & Low & $18.0-32.0 \mathrm{mmol} / 1$ \\
Urea & $27 \mathrm{mg} / \mathrm{dl}$ & Normal & $10.0-50.0 \mathrm{mg} / \mathrm{dl}$ \\
Creatinine & $1.34 \mathrm{mg} / \mathrm{dl}$ & High & $0.5-1.10 \mathrm{mg} / \mathrm{dl}$ \\
PCV & $38 \%$ & Normal & $37-47 \%$ \\
TWBC & $27,900 \mathrm{cells} / \mathrm{mm}^{3}$ & High & $4000-11000 \mathrm{cells} / \mathrm{mm}^{3}$ \\
Neutrophils & $82.7 \%$ & High & $40-75 \%$ \\
Lymphocytes & $7.3 \%$ & Low & $20-45 \%$ \\
Others & $10 \%$ & High & $0-7 \%$ \\
Platelets & $231,000 / \mathrm{mm}^{3}$ & Normal & $150,000-450000 / \mathrm{mm}^{3}$ \\
Urine Ketone & $3+$ & High & Negative \\
\hline
\end{tabular}

$\mathrm{Na}$ - Sodium, $\mathrm{K}$ - Potassium, $\mathrm{Cl}$ - Chloride, $\mathrm{HCO}_{3}$-Bicarbonate, PCV - Packed Cell Volume, TWBC - Total White Blood Cells.

AP was commenced on intravenous Normal Saline at $10 \mathrm{ml} / \mathrm{kg}$ in the first hour, with deficit and maintenance fluid given over the next 48 hours. She also received three doses of intravenous mannitol $(0.5 \mathrm{mg} / \mathrm{kg})$ over 24 hours, along with furosemide to treat early-onset cerebral oedema. Hyperglycaemia was corrected as per the unit protocol with subcutaneous soluble insulin. She was placed on broad- 
spectrum antibiotics (Intravenous Ceftriaxone $1 \mathrm{~g}$ twice daily).

Subsequently, the random blood glucose range over the next three days was between $169 \mathrm{mg} / \mathrm{dl}$ and $394 \mathrm{mg} / \mathrm{dl}$ and fever had subsided by the third day of admission. Consciousness level gradually improved and was recorded as GCS of $10 / 15$ on the third day of admission, at which time paresis of the left side of the body was noted. She regained full consciousness on the fifth day of admission with the persistence of the weakness of the left side of the body. A diagnosis of a right hemispheric ischaemic stroke was made and was confirmed by neuroimaging, which showed the presence of multiple lacunar infarcts in both cerebral hemispheres. (Figure 1) She regained full muscle activity by the tenth day of admission and was later discharged on subcutaneous basal-bolus insulin. No neurological sequela was noticed two years later.

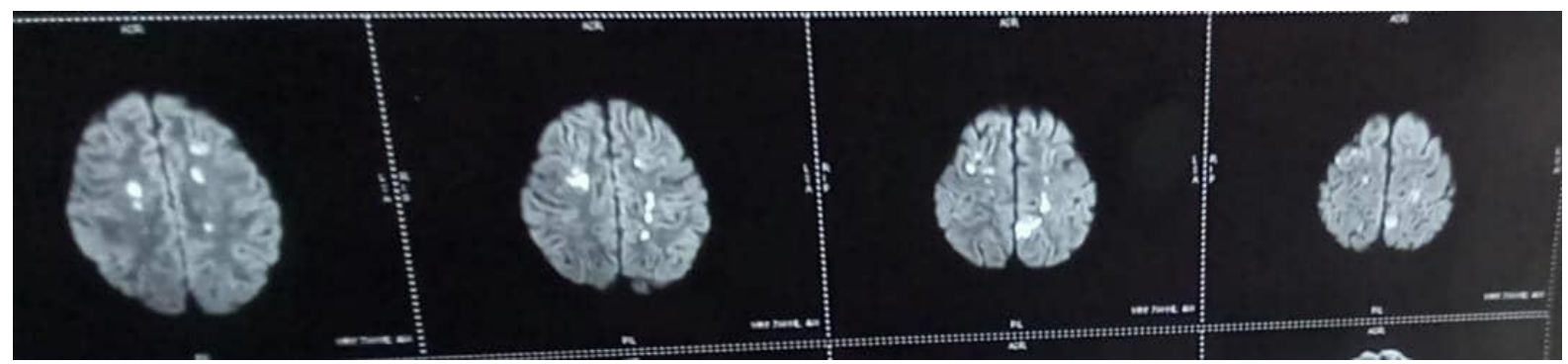

Figure 1: Coronal view of Brain MRI showing multiple small foci of restricted diffusion in both cerebral hemispheres

\section{Discussion}

Cerebral oedema is the most reported of the rare complications of DKA in children. [11] Perhaps CVA, another rare complication of DKA, has received less attention in the literature because it may have been frequently missed. Both complications share clinical features of generalized body weakness, headache, confusion, altered sensorium and increased respiratory rate. [8] These notable common features make diagnosis and distinction between the two conditions challenging, particularly when the patient cannot communicate. The diagnosis of DKA-related cerebral oedema in the index patient was based on the history of copious intravenous fluid infusion, unconsciousness, tachypnoea and sluggish pupillary reflex in a known patient with T1DM. These have earlier been described as early signs of DKA-related cerebral oedema. ${ }^{[12]}$ Some reports also indicate that children who have had higher fluid volume and rapid correction of hyperglycaemia are more prone to develop overt cerebral oedema. ${ }^{[13]}$ All researchers may not share this view as other reports indicate that cerebral oedema may occur from early ischaemic brain damage followed by reperfusion injury during treatment. [11, 14]

It is difficult to determine the onset of CVA in the index patient as she presented in an unconscious state. The focal sign of paresis, which led to the diagnosis, was only discovered as she regained consciousness and moved her limbs actively. This feature occurs in the minority of patients as less than $30 \%$ of patients with DKA-associated CVA have characteristic focal neurologic deficits. [9] Even though the mechanism of ischaemic CVA in children is not yet fully understood, DKA has been associated with tissue ischaemia. [8] Risk factors for CVA include metabolic abnormalities, 
sickle cell anaemia, congenital heart disease, coagulopathies and infections.[4] The index patient had two risk factors: metabolic acidosis and leucocytosis.

An early brain MRI is highly recommended to confirm the diagnosis of CVA and ascertain the outset of CVA and other neurological impairment in patients with DKA. [11] In addition, CVA should be suspected in patients with DKA who do not respond to conventional treatment. The index patient had brain imaging studies that confirmed the diagnosis of CVA. Unfortunately, this may not be possible in resource-poor settings. Therefore all clinicians should have a high index of suspicion for CVA when managing children with DKA.

The clinical presentation of the index patient is similar to the report of Oludare et al. [15] in Southwestern Nigeria. The cases were referred for higher-level management, but they developed focal neurological deficits, which alerted the clinicians to brain imaging. Both patients, however, made a full recovery before discharge. Without a doubt, many of such cases may have been missed. It is also possible that some CVA mortality may have been erroneously attributed to DKA- associated cerebral oedema. [16]

It is essential to maintain hydration in all patients with DKA as hyperglycaemia and dehydration are potentially prothrombotic states and are associated with increased risk of intravascular thromboembolism. [8] Generally, the use of thrombolytic agents, adequate hydration, diet restrictions, infection control, physiotherapy, temperature and glycaemic control are important measures in managing children with DKA and CVA. ${ }^{[8]}$ The use of thrombolytic agents for the treatment of paediatric CVA remains controversial, as few studies have documented its use. [11, 17] The index patient had careful attention paid to all the afore-mentioned measures but did not receive any thrombolytic agent.

\section{Conclusion}

A cerebrovascular accident, a rare complication of DKA, can occur as a complication of cerebral oedema or as an isolated case without cerebral oedema. Clinicians managing children with DKA should be aware of this complication as it can negatively affect the outcome and prolong hospital stay.

Declaration: Parental consent was obtained to publish the report.

Acknowledgement: The authors are thankful to the health care workers who participated in the management of this case.

Authors' Contributions: IJA conceived the research and drafted the manuscript with AG. All the authors participated in the literature review, revision of the draft for sound intellectual contents and approved the final version of the manuscript.

Conflicts of Interest: None.

Funding: Self-funded.

Publication History: Submitted 02 November 2021; Accepted 09 December 2021.

\section{References}

1. Curtis JR, To T, Muirhead S, Cummings E, Daneman D. Recent trends in hospitalization for diabetic ketoacidosis in Ontario children. Diabetes Care 2002; 25: 1591-1596. https://doi.org/10.2337/ diacare.25.9.1591

2. Edge JA, Ford-Adams ME, Dunger DB. Causes of death in children with insulin-dependent diabetes 1990-96. Arch Dis Child 1999; 81: 318323. https://doi.org/10.1136/adc.81.4.318

3. Otieno CF, Kayima JK, Omonge EO, Oyoo GO. Diabetic ketoacidosis: risk factors, mechanisms and management strategies in sub-Saharan Africa: a review. East Afr Med J 2005; 82: $197-$ 203. https://doi.org/10.4314/eamj.v82i12.9382 
4. Azad C, Kaur R, Singh DK, Arya A. Stroke in Pediatric diabetic ketoacidosis: Case series. J Trop Pediatr 2017; 63: 324-327. https://doi.org/10.1093/tropej/fmw088

5. Ahuja W, Kumar N, Kumar S, Rizwan A. Precipitating risk factors, clinical presentation, and outcome of diabetic ketoacidosis in patients with type 1 diabetes. Cureus 2019; 11: 47-89 https://doi.org/10.7759/cureus.4789

6. Ehrmann D, Kulzer B, Roos T, Haak T, AlKhatib M, Hermanns N. Risk factors and prevention strategies for diabetic ketoacidosis in people with established type 1 diabetes. The Lancet Diabetes Endocrinol 2020; 8: 436-446. https://doi.org/10.1016/s2213-8587(20)30042-5

7. Rosenbloom AL. Intracerebral crises during treatment of diabetic ketoacidosis. Diabetes Care. 1990; 13: 22-33. https://doi.org/10.2337/diacare.13.1.22

8. Jovanovic A, Stolic RV, Rasic DV, MarkovicJovanovic SR, Peric VM. Stroke and diabetic ketoacidosis-some diagnostic and therapeutic considerations. Vasc Health Risk Manag 2014; 10: $\quad$ 201-204. https:// doi.org/10.2147/VHRM.S59593

9. Foster JR, Morrison G, Fraser DD. Diabetic ketoacidosis-associated stroke in children and youth. Stroke Res Treat 2011; 22: 4 2011:219706. https://doi.org/10.4061/2011/219706

10. CDC Growth Charts. Available at https://www.cdc.gov/growthcharts/clinical_c harts.htm (Accessed on 01 July 2021.)

11. Bialo SR, Agrawal S, Boney CM, Quintos JB. Rare complications of Paediatric diabetic ketoacidosis. World J Diabetes 2015; 6: 167-174. https:// doi.org/10.4239/wjd.v6.i1.167
12. Levin DL. Cerebral edema in diabetic ketoacidosis. Pediatric Critical Care Medicine 2008; $\quad 9$ 320-329. https://doi.org/10.1097/PCC.0b013e31816c708 $\underline{2}$

13. Azova S, Rapaport R, Wolfsdorf J. Brain injury in children with diabetic ketoacidosis: Review of the literature and a proposed pathophysiologic pathway for the development of cerebral oedema. Pediatr Diabetes 2021; 22: 148-160. https://doi.org/10.1111/pedi.13152

14. Glaser NS, Ghetti S, Casper TC, Dean JM, Kuppermann N, Pediatric Emergency Care Applied Research Network (PECARN) DKA FLUID Study Group. Pediatric diabetic ketoacidosis, fluid therapy, and cerebral injury: the design of a factorial randomized controlled trial. Pediatric Diabetes 2013; 14): 435-446. https://doi.org/10.1111/pedi.12027

15. Oludare OI, Oluwasola OJ, Fesojaye TA. Cerebrovascular disease in a newly diagnosed diabetic adolescent: case report. Endocrinol Metab Int J 2017; 5: 185-186. https://doi.org/10.15406/emij.2017.05.00114

16. Gosmanov AR, Gosmanova EO, Kitabchi AE. Hyperglycemic crises: diabetic ketoacidosis (DKA), and hyperglycemic hyperosmolar state (HHS). In: Endotext [Internet]. South Darthmouth (MA): MD Text.com. Inc,; 20002021 May 09.

17. Ferriero DM, Fullerton $\mathrm{HJ}$, Bernard $\mathrm{TJ}$, Billinghurst L, Daniels SR, DeBaun MR, deVeber G, Ichord RN, Jordan LC, Massicotte P, Meldau J. Management of stroke in neonates and children: a scientific statement from the American Heart Association/American Stroke Association. Stroke 2019; 50: e51-e96. https://doi.org/10.1161/STR.000000000000018 $\underline{3}$ 